\title{
The Cerebellum and Cerebello-Thalamo-Cortical Channels Contribute to New Learning and Long-Term Memory of Motor Skill Xiaofeng $\mathrm{Lu}^{1,2,3 *}$
}

${ }^{1}$ Brain Sciences Center, Veterans Administration Medical Center, Minneapolis, Minnesota 55417, USA

${ }^{2}$ Department of Neurology, School of Medicine, University of Minnesota, Minneapolis, Minnesota 55414, USA

${ }^{3}$ Department of Neurophysiology, School of Medicine, Juntendo University, Tokyo, Japan

\begin{abstract}
Why do we have a cerebellum, a little brain? Although the cerebellum contains as many neurons as there are in the cerebral cortex, we are curiously poorly informed about the finer details of its function. Recent anatomical studies have revealed cerebellar projections from the separate portions of the interpositus nuclei into the primary motor cortex (M1) and prefrontal cortex. These findings suggest that the cerebellum might not only play a role in motor control but also in cognitive domains. In particular, we discuss here that these new neural pathways provide a neural substrate for acquisition and retention of motor learning.
\end{abstract}

$\mathrm{Lu}$ and his research team used the retrograde transneuronal transport of rabies virus to identify neurons in the cerebellar nuclei that project via the thalamus to the cerebral cortex of macaques. In particular, projections from deep cerebellar nuclei to area 46 of the prefrontal cortex were compared with projections to the primary motor cortex (M1). They found that, after viral injections into area 46, many labeled neurons were observed in the ventral aspect of the Posterior Interpositus Nucleus (PIN), whereas no neuron labeling was found in the Anterior Interpositus Nucleus (AIN). In contrast, a number of labeled neurons were found in the dorsal portion of the PIN after viral injections into the M1. Additionally, neurons labeled from the M1 injections were also observed in the AIN [1-3]. These findings demonstrate that the cerebellar interpositus nuclei possess distinct outputs to the prefrontal cortex versus the M1, which potentially contribute to different aspects of behavioral functions such as different stages of the motor learning.

Medial cerebellar outputs from the interpositus nuclei have been thought to be crucial for the associative motor learning. McCormick and Thompson have reported that lesions of the interpositus nuclei abolished the memorized eyeblink response; recordings from these nuclei have revealed neuronal activity to response learning [4]. Yet, clinical studies have reported that initial stage of trace eyeblink conditioning learning was impaired in patients with lesions in the PIN [5]. Imaging studies have also shown that the cerebellum play a key role in eyeblink conditioning [6-8]. Moreover, significant changes of positron emission tomography and regional cerebral blood flow in several areas, including the cerebellum and the prefrontal cortex, were observed during performance of associative motor learning task [9]. The above, taken together with the new medial cerebellar channels from the posterior interpositus nucleus to area 46 of the prefrontal cortex, it is reasonable to hypothesize that the cerebellum and cerebello-thalamocortical channels contribute to motor learning.

The medial cerebellar output from the ventral PIN and the dorsal PIN/AIN play differential roles in various steps of the motor learning $[5,10,11]$. The dorsal aspect of the PIN has been thought to contribute to performance of memorized motor responses such as eyeblink and saccadic eye movements rather than to their initial learning $[10,11]$. If this is the case, then impairment in the acquisition of the new learning by lesions of the PIN could be due to functional blockade of the ventral rather than dorsal portion of the PIN [5].

Furthermore, previous studies have shown evidence that the expression of representative motor memory formation genes was increased selectively in the AIN, but not in the PIN [12]. This finding strongly suggests that the AIN is involved in the storage and/or retrieval of long-term memory of motor learning. Moreover, many studies have indicated that the AIN is the site for long-term memory rather than new learning during practice of the eyeblink conditioning response. Examples include lesion [13-17]; inactivation [18,19]; electron microscopy [20]; functional magnetic resonance imaging [21]. Given the above, it is natural to raise a theory that the medial cerebellar output from the ventral PIN and the dorsal PIN/AIN plays a critical role in the new learning and long-term memory, respectively, during the motor learning processing.

Interestingly, different cortical areas have been thought to be involved in these various steps of motor learning. A considerable theory for motor learning indicates that new learning is an explicit process originating in the prefrontal cortex, and that the long term memory for the learned motor skill becomes automatic and an implicit process formed in the motor cortex [22-24]. Thus, the disynaptic pathway from the ventral aspect of the PIN to area 46 may be involved in the initiation of the association of motor learning. After repeated practice, cerebellar channels to the M1 originating from the dorsal PIN/AIN turn to play a key role in the storage and/or retrieval of long-term memory, which makes the association automatic.

Last, neuropsychological testing of patients with cerebellar lesions has revealed specific deficits in different faculties, including visual perception [25-31], short-term memory [32,33], or verbal fluency [34]. Moreover, clinical studies have shown that, in the brains of subjects with autism, the most consistent abnormalities are found in cerebellar Purkinje cells [35]. Accordingly, the questions of whether and how these cerebello-thalamo-cortical channels and their involvements in

*Corresponding author: Xiaofeng Lu, Research Physiologist, VA Medical Center, Minneapolis, USA, E-mail: luxxx049@umn.edu

Received March 26, 2013; Accepted March 28, 2013; Published March 30, 2013

Citation: Lu X (2013) The Cerebellum and Cerebello-Thalamo-Cortical Channels Contribute to New Learning and Long-Term Memory of Motor Skill. Brain Disord Ther 2: e106. doi:10.4172/2168-975X.1000e106

Copyright: (c) 2013 Lu X. This is an open-access article distributed under the terms of the Creative Commons Attribution License, which permits unrestricted use, distribution, and reproduction in any medium, provided the original author and source are credited. 
Citation: Lu X (2013) The Cerebellum and Cerebello-Thalamo-Cortical Channels Contribute to New Learning and Long-Term Memory of Motor Skill. Brain Disord Ther 2: e106. doi:10.4172/2168-975X.1000e106

different stages of learning relate to those cerebellar deficits remain to be answered.

\section{Conclusion}

In conclusion, this review discusses fundamental neural mechanisms for the involvement of medial cerebellar output from the interpositus nuclei in cognitive functions such as acquisition and retention during motor learning. This provides useful information for understanding the processing of cerebellar outputs to cognitive function.

\section{Acknowledgement}

This work was supported by Grants-in-Aid for Scientific Research (18500247 and 20500293) to X.L. from the Ministry of Education, Culture, Sports, Science, and Technology of Japan.

\section{References}

1. Lu X, Miyachi S, Ito Y, Nambu A, Takada M (2007) Topographic distribution of output neurons in cerebellar nuclei and cortex to somatotopic map of primary motor cortex. Euro J Neurosci 25: 2374-2382.

2. Lu X, Miyachi S, Takada M (2012) Anatomical evidence for the involvement of medial cerebellar output from the interpositus nuclei in cognitive functions. Proc Natl Acad Sci U S A 109: 18980-18984.

3. Lu X (2012) Organization of cerebellar outputs to primary motor cortex and prefrontal cortex. Brain Disord Ther 1:3 1000e104

4. McCormick DA, Thompson RF (1984) Cerebellum: essential involvement in the classically conditioned eyelid response. Science 223: 296-299.

5. Gerwig M, Haerter K, Hajjar K, Dimitrova A, Maschke M, et al. (2006) Trace eyeblink conditioning in human subjects with cerebellar lesions. Exp Brain Res 170: 7-21.

6. Logan CG, Grafton ST (1995) Functional anatomy of human eyeblink conditioning determined with regional cerebral glucose metabolism and positron-emission tomography. Proc Natl Acad Sci USA 92: 7500-7504.

7. Blaxton TA, Zeffiro TA, Gabrieli JD, Bookheimer SY, Carrillo MC, et al. (1996) Functional mapping of human learning: a positron emission tomography activation study of eyeblink conditioning. J Neurosci 16: 4032-4040.

8. Schreurs BG, Mclntosh AR, Bahro M, Herscovitch P, Sunderland T, et al. (1997) Lateralization and behavioral correlation of changes in regional cerebral blood flow with classical conditioning of the human eyeblink response. J Neurophysiol 77: 2153-2163.

9. Molchan SE, Sunderland T, Mclntosh AR, Herscovitch P, Schreurs BG (1994) A functional anatomical study of associative learning in humans. Proc Natl Acad Sci USA 91: 8122-8126.

10. Lu X, Hikosaka O, Miyachi S (1998) Role of monkey cerebellar nuclei in skill for sequential movement. J Neurophysiol 79: 2245-2254

11. Gruart A, Guillazo-Blanch G, Fernandez-Mas R, Jimenez-Diaz L, DelgadoGarcia JM (2000) Cerebellar posterior interpositus nucleus as an enhancer of classically conditioned eyelid responses in alert cats. J Neurophysiol 84: 26802690

12. Park JS, Onodera T, Nishimura S, Thompson RF, Itohara S (2006) Molecular evidence for two-stage learning and partial laterality in eyeblink conditioning of mice. Proc Natl Acad Sci USA 103: 5549-5554.

13. Lavond DG, Hembree TL, Thompson RF (1985) Effect of kainic acid lesions of the cerebellar interpositus nucleus on eyelid conditioning in the rabbit. Brain Res 326: 179-182.

14. Skelton RW (1988) Bilateral cerebellar lesions disrupt conditioned eyelid responses in unrestrained rats. Behav Neurosci 102: 586-590.
15. Steinmetz JE, Lavond DG, Ivkovich D, Logan CG, Thompson RF (1992) Disruption of classical eyelid conditioning after cerebellar lesions: damage to a memory trace system or a simple performance deficit? J Neurosci 12: 44034426.

16. Woodruff-Pak DS, Lavond DG, Logan CG, Steinmetz JE, Thompson RF (1993) Cerebellar cortical lesions and reacquisition in classical conditioning of the nictitating membrane response in rabbits. Brain Res 608: 67-77.

17. Swain RA, Shinkman PG, Thompson JK, Grethe JS, Thompson RF (1999) Essential neuronal pathways for reflex and conditioned response initiation in an intracerebellar stimulation paradigm and the impact of unconditioned stimulus preexposure on learning rate. Neurobiol Learn Mem 71: 167-193.

18. Chapman PF, Steinmetz JE, Sears LL, Thompson RF (1990) Effects of lidocaine injection in the interpositus nucleus and red nucleus on conditioned behavioral and neuronal responses. Brain Res 537: 149-156.

19. Bao S, Chen L, Kim JJ, Thompson RF (2002) Cerebellar cortical inhibition and classical eyeblink conditioning. Proc Natl Acad Sci USA 99: 1592-1597.

20. Kleim JA, Freeman JH Jr, Bruneau R, Nolan BC, Cooper NR, et al. (2002) Synapse formation is associated with memory storage in the cerebellum. Proc Natl Acad Sci USA 99: 13228-13231.

21. Miller MJ, Chen NK, Li L, Tom B, Weiss C, et al. (2003) fMRI of the conscious rabbit during unilateral classical eyeblink conditioning reveals bilateral cerebellar activation. J Neurosci 23: 11753-11758.

22. Hikosaka O, Nakahara H, Rand MK, Lu X, Nakamura K, et al. (1999) Paralle neural networks for learning sequential procedures. Trends Neurosci 22: 464 471

23. Lu X, Ashe J (2005) Anticipatory activity in primary motor cortex codes memorized movement sequences. Neuron 45: 967-973.

24. Ashe J, Lungu OV, Basford, AT, Lu X (2006) Cortical control of motor sequences Curr Opin Neurobiol 16: 213-221.

25. Ivry R, Diener HC (1991) Impaired velocity perception in patients with lesions of the cerebellum. J Cogn Neurosci 3: 355-365.

26. Nawrot M, Rizzo M (1995) Motion perception deficits from midline cerebellar lesions in human. Vision Res. 35: 723-731.

27. Nawrot M, Rizzo M (1998) Chronic motion perception deficits from midline cerebellar lesions in human. Vision Res. 38: 2219-2224.

28. Schmahmann JD, Sherman JC. (1998) The cerebellar cognitive affective syndrome. Brain 121: 561-579.

29. Thier P, Haarmeier T, Treue S, Barash S (1999) Absence of a common functional denominator of visual disturbances in cerebellar disease. Brain 122 2133-2146.

30. Jokisch D, Troje NF, Koch B, Schwarz M, Daum I (2005) Differential involvement of the cerebellum in biological and coherent motion perception. Eur J Neurosc 21: $3439-3446$

31. Maschke M, Gomez CM, Tuite PJ, Pickett K, Konczak J (2006) Depth perception in cerebellar and basal ganglia disease. Exp Brain Res 175: 165-176.

32. Ravizza SM, McCormick CA, Schlerf JE, Justus T, Ivry RB, et al. (2006) Cerebellar damage produces selective deficits in verbal working memory. Brain 129: 306-320.

33. Haarmeier T, Thier P (2007) The attentive cerebellum - myth or reality? Cerebellum 6: 177-183.

34. Richter S, Gerwig M, Aslan B, Wilhelm H, Schoch B, et al. (2007) Cognitive functions in patients with MR-defined chronic focal cerebellar lesions. J Neurol. 254:1193-203

35. Ritvo ER, Freeman BJ, Scheibel AB, Duong T, Robinson H, et al. (1986) Lowe Purkinje cell counts in the cerebella of four autistic subjects: initial findings of the UCLA-NSAC Autopsy Research Report. Am J Psychiatry. 143: 862-866. 